\title{
Comparative analysis of Vening-Meinesz Moritz isostatic models using the constant and variable crust-mantle density contrast - a case study of Zealandia
}

\author{
Mohammad Bagherbandi ${ }^{1,2}$ and Robert Tenzer ${ }^{3, *}$ \\ ${ }^{1}$ Division of Geodesy and Geoinformatics, Royal Institute of Technology (KTH), SE-10044 Stockholm, Sweden. \\ ${ }^{2}$ Department of Industrial Development, IT and Land Management, University of Gävle, SE-80176 Gävle, Sweden. \\ ${ }^{3}$ Institute of Geodesy and Geophysics, School of Geodesy and Geomatics, Wuhan University, \\ 129 Luoyu Road, Wuhan, China. \\ *Corresponding author.e-mail: rtenzer@sgg.whu.edu.cn
}

\begin{abstract}
We compare three different numerical schemes of treating the Moho density contrast in gravimetric inverse problems for finding the Moho depths. The results are validated using the global crustal model CRUST2.0, which is determined based purely on seismic data. Firstly, the gravimetric recovery of the Moho depths is realized by solving Moritz's generalization of the Vening-Meinesz inverse problem of isostasy while the constant Moho density contrast is adopted. The Pratt-Hayford isostatic model is then facilitated to estimate the variable Moho density contrast. This variable Moho density contrast is subsequently used to determine the Moho depths. Finally, the combined least-squares approach is applied to estimate jointly the Moho depths and density contract based on a priori error model. The EGM2008 global gravity model and the DTM2006.0 global topographic/bathymetric model are used to generate the isostatic gravity anomalies. The comparison of numerical results reveals that the optimal isostatic inverse scheme should take into consideration both the variable depth and density of compensation. This is achieved by applying the combined least-squares approach for a simultaneous estimation of both Moho parameters. We demonstrate that the result obtained using this method has the best agreement with the CRUST2.0 Moho depths. The numerical experiments are conducted at the regional study area of New Zealand's continental shelf.
\end{abstract}

\section{Introduction}

The earth's crust structure and its thickness are typically determined using seismic data. Over large areas of the world, where seismic data are not yet available or their spatial coverage is insufficient, gravimetric or combined methods can be applied due to the global coverage and a relatively detailed resolution of the currently available global geopotential models. The principle of classical isostatic models, such as the Airy-Heiskanen and Pratt-Hayford (Heiskanen and Moritz 1967), is based on a local compensation of topographic masses.

According to the Pratt-Hayford hypothesis, the isostatic compensation is uniform as the density of mountains is smaller than the density under lowlands. Moreover, the compensation layer is stipulated at the depth of compensation of about $100 \mathrm{~km}$, where the isostatic equilibrium occurs (Heiskanen and Vening Meinesz 1958). Vening Meinesz (1931) modified the Airy-Heiskanen theory of isostasy with applying the regional instead of local compensation. Moritz (1990) utilized the

Keywords. Crust; gravity; isostatic model; Moho interface. 
Vening-Meinesz inverse problem in solving the isostatic-gravimetric model for finding the Moho depths. Sjöberg (2009) further generalized this concept for finding the Moho depths and density contrast. Sjöberg and Bagherbandi (2011) developed and applied the combined least-squares method for a joint estimation of both Moho parameters. This method requires an optimal choice of the covariance matrix of known parameters for solving the system of normal equations. If both parameters are unknown, the problem has no unique solution. The least-squares solution can thus be found only if the a priori estimates of the unknown parameters and their standard errors are known approximately. Sjöberg and Bagherbandi (2012) demonstrated the advantage of using the combined least-squares method compared to the Airy-Heiskanen model. Bagherbandi and Sjöberg (2011) computed the Moho depths based on solving Moritz's generalization of the Vening-Meinesz inverse problem of isostasy (VMM isostatic model). They demonstrated that the VMM Moho depths generally better agree with CRUST2.0 data than those obtained from using the Airy-Heiskanen isostatic model.

In this study we apply and compare three different numerical schemes of treating the Moho density contrast for finding the Moho depths based on solving VMM isostatic model. In particular, we assume that the constant and variable Moho density contrasts are a priori known while solving the VMM isostatic model for finding the Moho depths. Then, both Moho parameters are estimated jointly in the least-squares scheme. The numerical analysis is conducted at the study area of New Zealand and its continental shelf (Zealandia). The primary purpose of this analysis is to establish the optimal isostatic model for this study area with a low coverage of seismic data. We also discuss and identify some theoretical limitations of applied isostatic models. The treatment of these non-isostatic effects is out of the scope of this study.

\section{Vening Meinesz-Moritz isostatic model}

The principle of solving Moritz's generalization of the Vening-Meinesz inverse problem of isostasy is based on generating the isostatic gravity anomalies, which equal zero under the assumption of varying Moho depths $T$, while adopting a constant value of the Moho density contrast $\Delta \rho=$ $\rho^{m}-\rho^{c}$; where $\rho^{c}$ and $\rho^{m}$ denote the constant density values of the earth's crust and the encompassing upper(most) mantle, respectively. The isostatic gravity anomaly $\Delta g^{i}$ computed at a position $(r, \Omega)$ is defined as follows (Vening Meinesz 1931):

$$
\Delta g^{i}(r, \Omega)=\Delta g^{B}(r, \Omega)+g^{c}(r, \Omega)=0,
$$

where $\Delta g^{B}$ is the refined Bouguer gravity anomaly, and $g^{c}$ is the gravitational attraction of isostatic compensation masses (Bjerhammar 1962, chap. 14, equation 5; Moritz 1990). The 3-D position is defined in the system of spherical coordinates $(r, \Omega)$, where $r$ is the spherical radius and $\Omega=$ $(\phi, \lambda)$ denotes the spherical direction with the spherical latitude $\phi$ and longitude $\lambda$.

Sjöberg (2009) derived the VMM inverse problem of isostasy in the following generic form

$$
R \iint_{\Phi} K(\psi, s) d \Omega^{\prime}=f(r, \Omega),
$$

where $R=6371 \times 10^{3} \mathrm{~m}$ is the earth's mean radius (which approximates the geocentric radii of the geoid surface); the parameter $s$ of the integral kernel function $K$ reads $s=1-\tau=1-T / R$ and the kernel parameter $\psi$ is the spherical distance between two points $(r, \Omega)$ and $\left(r^{\prime}, \Omega^{\prime}\right)$. The infinitesimal surface element on the unit sphere is denoted as $d \Omega^{\prime}=\cos \phi^{\prime} d \phi^{\prime} d \lambda^{\prime}$, and $\Phi=$ $\left\{\Omega^{\prime}=\left(\phi^{\prime}, \lambda^{\prime}\right): \phi^{\prime} \in[-\pi / 2, \pi / 2] \wedge \lambda^{\prime} \in[0,2 \pi)\right\}$ is the full spatial angle. The isostatic gravity anomaly functional $f$ is defined as:

$$
f(r, \Omega)=-\frac{1}{G \Delta \rho}\left[\Delta g^{\mathrm{B}}(r, \Omega)+g_{0}^{c}(r, \Omega)\right],
$$

where $G=6.674 \times 10^{-11} \mathrm{~m}^{3} \mathrm{~kg}^{-1} \mathrm{~s}^{-2}$ is Newton's gravitational constant. The spectral representation of the integral kernel function $K$ in equation (2) is given by Sjöberg (2009)

$$
K(\psi, s)=\sum_{n=0}^{\infty} \frac{n+1}{n+3}\left(1-s^{n+3}\right) P_{n}(\cos \psi),
$$

where $P_{n}$ is the Legendre polynomial of degree $n$ with the argument of cosine of the spherical distance $\psi$.

The expression in equation (2) is a nonlinear Fredholm integral equation of the first kind. A direct solution for finding the Moho depths $T$ was given by Sjöberg (2009) which is a second-order approximation. It reads:

$$
\begin{aligned}
T(\Omega)= & T_{1}(\Omega)+\frac{T_{1}^{2}(\Omega)}{R}-\frac{1}{32 \pi R} \\
& \times \iint_{\Phi} \frac{T_{1}^{2}\left(\Omega^{\prime}\right)-T_{1}^{2}(\Omega)}{\sin ^{3}(\psi / 2)} d \Omega^{\prime} .
\end{aligned}
$$

The term $T_{1}$ in equation (5) is computed as follows:

$$
T_{1}(\Omega)=\sum_{n=0}^{\infty}\left(2-\frac{1}{n+1}\right) \sum_{m=-n}^{n} f_{n, m} Y_{n, m}(\Omega),
$$


where $Y_{n, m}$ is the (fully-normalized) surface spherical harmonic function of degree $n$ and order $m$. The numerical coefficients $f_{n, m}$ of the isostatic gravity anomaly functional $f$ on the right-hand side of equation (6) are given by

$$
\begin{aligned}
f_{n, m}= & \frac{1}{4 \pi G \Delta \rho} \\
& \times\left\{\begin{array}{ll}
2 \pi G\left(\bar{\rho}^{c} H\right)_{0,0}-\tilde{g}_{0}^{c} & \text { if } n=0 \\
2 \pi G\left(\bar{\rho}^{c} H\right)_{n, m}-\Delta g_{n, m} & \text { otherwise }
\end{array} .\right.
\end{aligned}
$$

The numerical coefficients $f_{n, m}$ are computed from the spherical harmonic coefficients of the gravity anomaly $\Delta g_{n, m}$ after applying the spectral Bouguer gravity reduction term $2 \pi G\left(\bar{\rho}^{c} H\right)_{n, m}$ which is defined by means of the coefficients of global topographic/bathymetric (density) spherical functions $\left(\bar{\rho}^{c} H\right)_{n, m}$. The density distribution function $\bar{\rho}^{c}$ equals $\bar{\rho}^{c}=\rho^{c}$ on land, and the ocean density contrast is defined as $\bar{\rho}^{c}=\rho^{c}-\rho^{w}$, where $\rho^{w}$ is the mean seawater density. The nominal compensation attraction (of zero-degree) $\widetilde{g}_{0}^{c}$ stipulated at the sphere of radius $R$ is defined as (cf. Sjöberg 2009):

$$
\begin{aligned}
\widetilde{g}_{0}^{c} & =\left.g_{0}^{c}(r, \Omega)\right|_{r=R} \\
& =\frac{4}{3} \pi G \Delta \rho R\left[\left(1-\tau_{0}\right)^{3}-1\right] \\
& \approx-4 \pi G \Delta \rho T_{0},
\end{aligned}
$$

where $\tau_{0}=T_{0} / R$, and $T_{0}$ is the adopted nominal mean value of the Moho depths. The computation of the third constituent on the right-hand side of equation (5) is practically realized by limiting the surface integration area over the near zone while disregarding the contribution of the distant zone. The system of integral equations in equation (5) then gives the direct solution of the Moho depths without applying the iterative procedure. The third constituent on the right-hand side of equation (5) has a singularity for $\psi \rightarrow 0$. Sjöberg (2009) solved this integral singularity by applying the planar approximation to the near-zone contribution.

\section{Crust-mantle density contrast from the VMM model}

The constant value of the Moho density contrast was assumed in forming the observation equations for finding the Moho depths according to equation (2). The problem can be reformulated for finding the variable Moho density contrast $\Delta \rho$ while the Moho depths are a priori known. From equation (2), the generic expression for $\Delta \rho$ is given by Sjöberg and Bagherbandi (2011)

$$
R \iint_{\Phi} \Delta \rho\left(\Omega^{\prime}\right) K(\psi, s) d \Omega^{\prime}=b(r, \Omega),
$$

where the isostatic gravity anomaly functional $b$ reads:

$$
\begin{aligned}
b(r, \Omega) & =\Delta \rho f(r, \Omega) \\
& =-\frac{1}{G}\left[\Delta g^{B}(r, \Omega)+g^{c}(r, \Omega)\right] .
\end{aligned}
$$

As seen from comparing equations (2) and (9), the varying density contrast $\Delta \rho$ is now the unknown parameter. Substitution from equation (4) to equation (9) yields (Sjöberg and Bagherbandi 2011)

$$
\begin{aligned}
\Delta \rho(\Omega) \approx & \frac{b(r, \Omega)}{2 \pi T(\Omega)}-\frac{1}{16 \pi^{2} T(\Omega)} \\
& \times \iint_{\Phi} b\left(r^{\prime}, \Omega^{\prime}\right) H(\psi) d \Omega^{\prime} \\
& +\frac{T(\Omega) \Delta \rho(\Omega)}{R}-\frac{1}{32 \pi R T(\Omega)} \\
& \times \iint_{\Phi}\left[T^{2}\left(\Omega^{\prime}\right) \Delta \rho\left(\Omega^{\prime}\right)-T^{2}(\Omega) \Delta \rho(\Omega)\right] \\
& \times \sin ^{-3} \frac{\psi}{2} d \Omega^{\prime},
\end{aligned}
$$

where the integral kernel function $H(\psi)$ reads

$$
H(\psi)=\operatorname{cosec} \frac{\psi}{2}+\ln \left(1-\operatorname{cosec} \frac{\psi}{2}\right) .
$$

The observation equation in equation (11) for finding $\Delta \rho$ is solved iteratively.

\section{Combined least-squares model}

Based on the above defined isostatic models, Sjöberg and Bagherbandi (2011) introduced the combined least-squares approach for a joint estimation of the Moho depths and density contrast. They formulated the observation equations for $T \Delta \rho$ and $\Delta \rho$ as follows:

$$
\begin{aligned}
& T(\Omega) \Delta \rho(\Omega) \\
& =\sum_{n=0}^{\infty} \sum_{m=-n}^{n}\left[\frac{2 n+1}{4 \pi(n+1)} b_{n, m}-\frac{n+2}{2}\left(\Delta \rho T^{2}\right)_{n, m}\right] \\
& \quad \times Y_{n, m}(\Omega)
\end{aligned}
$$


and

$$
\begin{aligned}
\Delta \rho(\Omega)= & \frac{b(r, \Omega)}{2 \pi T(\Omega)}-\frac{1}{4 \pi T(\Omega)} \\
& \times \sum_{n=0}^{\infty} \sum_{m=-n}^{n}\left[\frac{1}{n+1}-\frac{T_{0} / R}{2 /(n+2)-T_{0} / R}\right] \\
& \times b_{n, m} Y_{n, m}(\Omega),
\end{aligned}
$$

where $b_{n, m}$ are spherical harmonics of the isostatic gravity anomaly functional $b$.

\section{Data acquisition}

The study area is bounded by the parallels of 20 and 70 arc-deg southern latitudes and the meridians of 150 and 210 arc-deg eastern longitudes. All computations were realized on a $2 \times 2$ arc-deg geographical grid. The coefficients of the Earth Gravitational Model 2008 (EGM2008; Pavlis et al. 2008) complete to the spherical harmonic degree 90 were used to generate the gravity anomalies on a $2 \times 2$ arc-deg grid at the Earth's surface. The refined Bouguer gravity anomalies were obtained from the EGM2008 gravity anomalies after applying the Bouguer gravity reduction. The spherical Bouguer gravity reduction was computed using the coefficients of the global topographic/bathymetric model DTM2006.0 (Pavlis et al. 2007) complete to the spherical harmonic degree 90 . The average density of the upper continental crust $2670 \mathrm{~kg} / \mathrm{m}^{3}$ (Hinze 2003) was adopted as the topographic and reference crust density. For the adopted values of the reference crust density $2670 \mathrm{~kg} / \mathrm{m}^{3}$ and the mean seawater density $1027 \mathrm{~kg} / \mathrm{m}^{3}$, the ocean density contrast equals $1643 \mathrm{~kg} / \mathrm{m}^{3}$. The earth's solid topography (i.e., topographic heights onshore and bathymetric depths offshore) generated on a $2 \times 2$ arc-deg grid using the DTM2006.0 topographic/bathymetric coefficients complete to degree/order of 90 is shown in figure 1 . The maximum topographic heights reach $1.2 \mathrm{~km}$ and the maximum bathymetric depths are $6.5 \mathrm{~km}$. The regional map of the refined Bouguer gravity anomalies compiled on a $2 \times 2$ arc-deg grid at the earth's surface with a spectral resolution complete to degree 90 of spherical harmonics is shown in figure 2. Within the study area the refined Bouguer gravity anomalies vary from -142 to $430 \mathrm{mGal}$ with the mean of $250 \mathrm{mGal}$ and the standard deviation is $102 \mathrm{mGal}$. The maxima correspond with the largest ocean depths, while the minima are located over New Zealand and its continental shelf (and the parts of Australia and Antarctica).

In the numerical model used for computing the refined Bouguer gravity anomalies according to

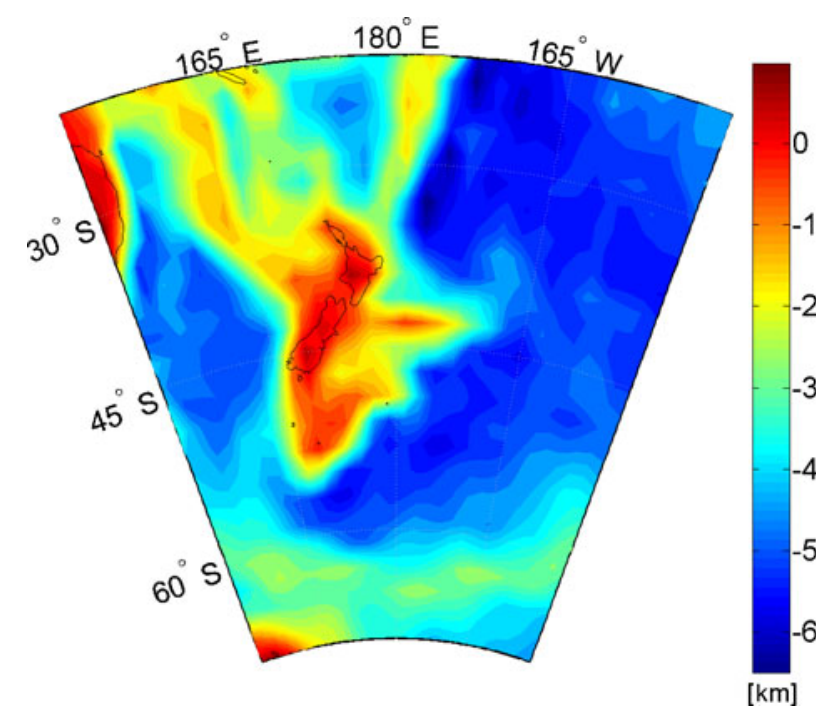

Figure 1. The earth's solid topography generated on a $2 \times$ 2 arc-deg grid using the DTM2006.0 coefficients complete to degree/order of 90 .

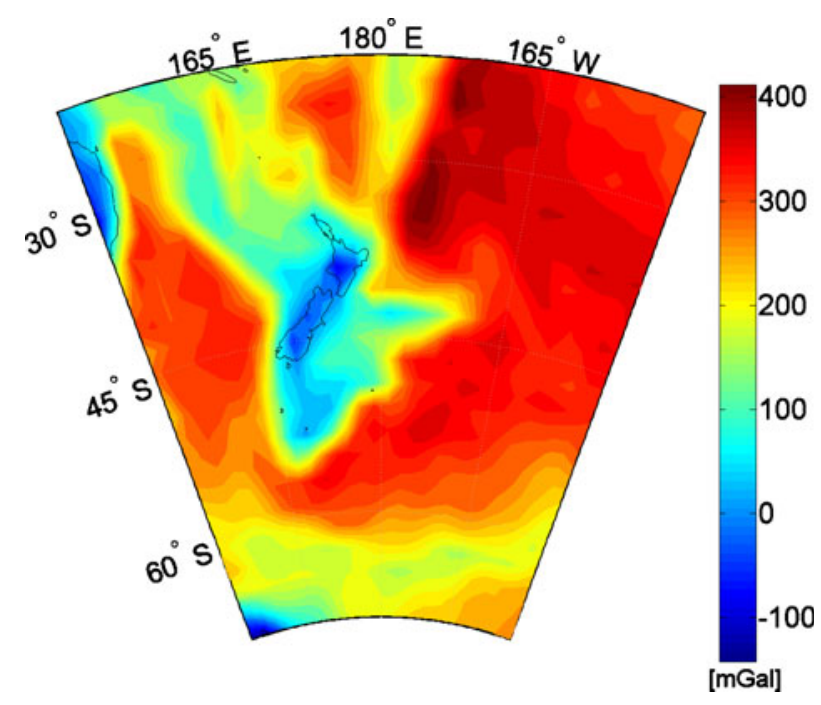

Figure 2. The refined Bouguer gravity anomalies computed on a $2 \times 2$ arc-deg grid at the surface points using the EGM2008 and DTM2006.0 coefficients complete to the spherical harmonic degree 90.

equation (7), the long-wavelength part of gravity spectra was not subtracted from results. It is, however, the well-known fact that due to thermal cooling of ocean floor, the long-wavelength thermal anomalies are detected that cause density variations within the oceanic upper mantle as well as variations of the oceanic lithospheric thickness. This long-wavelength gravity signal thus more likely propagates into the computed Bouguer gravity anomalies and consequently can influence the estimated Moho parameters. Similarly, the application of the simple Bouguer gravity reduction in mountainous regions with high elevations 
produces an unrealistic gravity signal due to the short-wavelength topography. The effect of this gravity signal on the estimated Moho parameters is to some extent reduced by applying the isostatic gravity term in equation (8).

\section{Results}

The VMM isostatic model was applied to determine the Moho depths assuming the constant Moho density contrast. The Pratt-Hayford isostatic model was then applied to determine the variable Moho density contrast with the subsequent estimation of the Moho depths (by solving the VMM isostatic model). Finally, the combined least-squares model was applied to estimate jointly both investigated Moho parameters.

The isostatic gravity anomalies were used to determine the Moho depths. This has been done based on solving the system of observation equations in equation (5). The input parameters of the (constant) Moho density contrast $\Delta \rho$ of $400 \mathrm{~kg} / \mathrm{m}^{3}$ and the mean Moho depth $T_{0}$ of $23 \mathrm{~km}$ were obtained by a spatial averaging of the $2 \times 2$ arc-deg CRUST2.0 data. The result is shown in figure 3. The VMM Moho depths vary from 5.3 to $37.5 \mathrm{~km}$ with the mean of $14.8 \mathrm{~km}$ and the standard deviation is $5.5 \mathrm{~km}$. The regional map of the Moho geometry in figure 3 revealed the major crustal structures with a larger continental crust thickness compared to a thinner oceanic one.

In order to reduce possible errors in estimated values of the Moho depths due to adopting the constant Moho density contrast, we further utilized the Pratt-Hayford isostatic model to determine the spatial variations of the Moho density contrast.

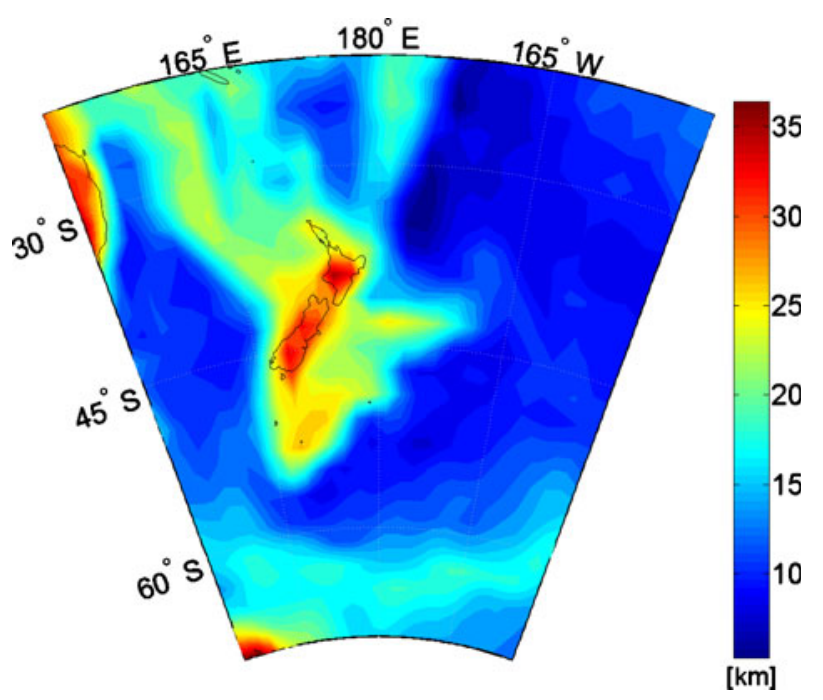

Figure 3. The VMM Moho depths.
The results are shown in figure 4 . The Moho density contrast varies between 418 and $573 \mathrm{~kg} / \mathrm{m}^{3}$ with the mean of $468 \mathrm{~kg} / \mathrm{m}^{3}$ and the standard deviation is $28 \mathrm{~kg} / \mathrm{m}^{3}$. The maxima are beneath the continental crust of New Zealand (and parts of Australia and Antarctica). The corresponding minima are beneath the Pacific Ocean and the central and southern parts of the Tasman Sea. These values of the variable Moho density contrast were further used to determine the Moho depths. The results are shown in figure 5 . The Moho depths now vary from 5.4 to $37.0 \mathrm{~km}$ with the mean of $15.3 \mathrm{~km}$ and the standard deviation is $5.4 \mathrm{~km}$.

The combined least-squares method was finally applied to estimate simultaneously both Moho parameters. Since our study area comprises the

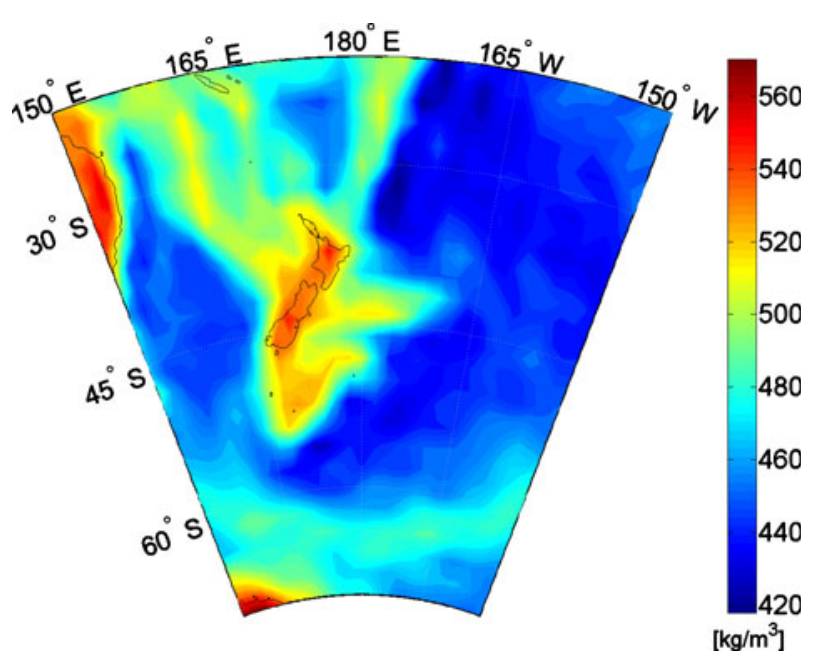

Figure 4. The crust-mantle density contrast values estimated based on the Pratt-Hayford isostatic model for the compensation depth of $100 \mathrm{~km}$.

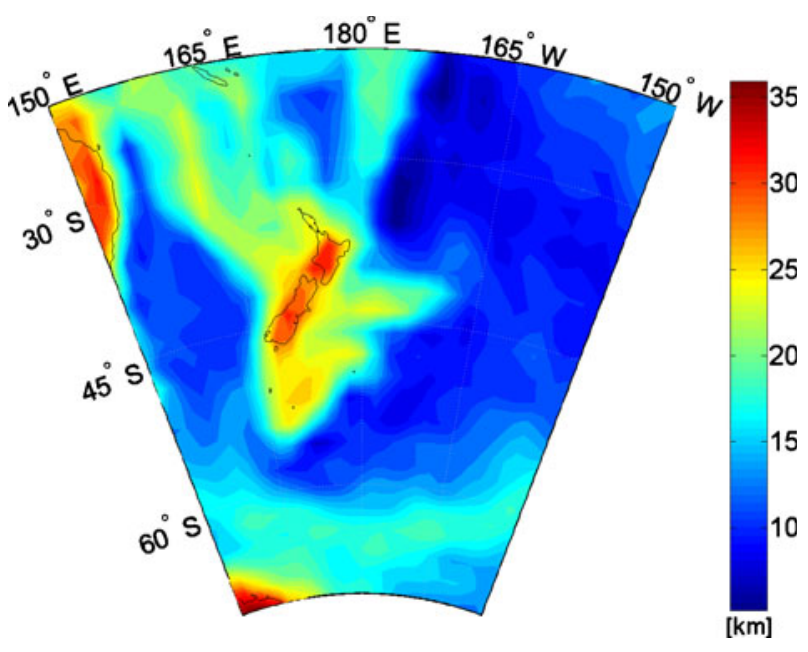

Figure 5. The VMM Moho depths computed based on the estimated variable crust-mantle density contrast (shown in figure 4). 
continental and oceanic crustal structures, two different values for the parameter $T_{0}$ in the observation equation of equation (14) we adopted. For the continental crust, we used the mean Moho depth of $36 \mathrm{~km}$, while the corresponding value of $13 \mathrm{~km}$ was chosen for the mean oceanic crust thickness. The initial values of Moho depths for forming the design matrix in the least-squares estimation model were taken from CRUST2.0. Since the CRUST2.0 Moho

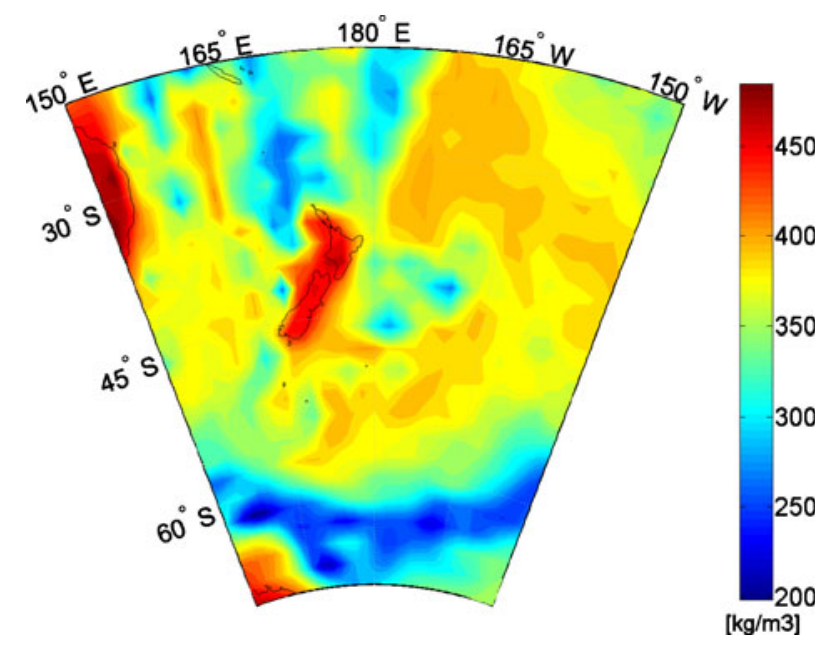

Figure 6. The variable crust-mantle density contrast estimated using the combined least-squares method.

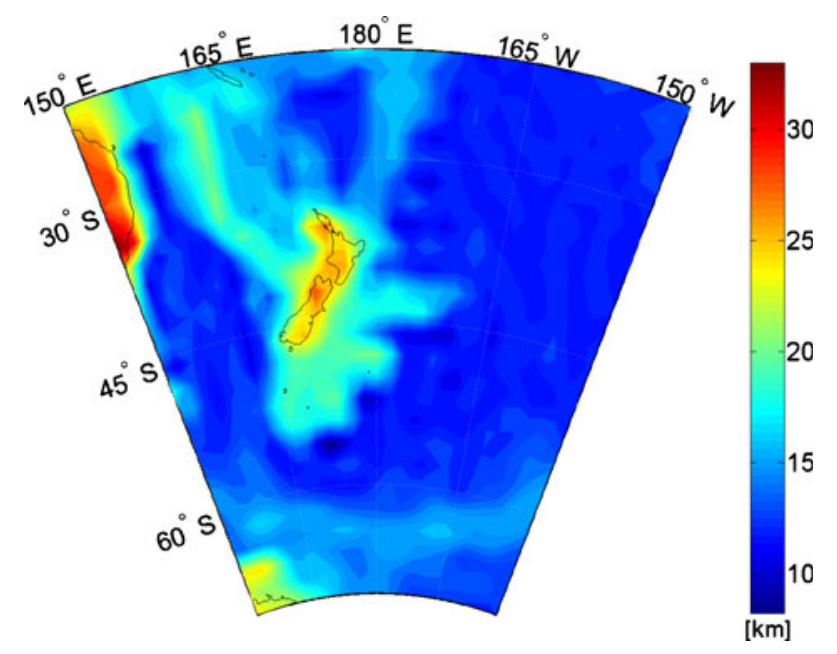

Figure 7. The Moho depths estimated using the combined least-squares method. depths data are not provided with the standard error model, we assumed the representative uncertainties in the Moho depth data of about 20\%. The least-squares results of the estimated Moho parameters are presented in figures 6 and 7 . The Moho density contrast varies between 199 and $492 \mathrm{~kg} / \mathrm{m}^{3}$ with the mean of $356 \mathrm{~kg} / \mathrm{m}^{3}$ and the standard deviation is $49 \mathrm{~kg} / \mathrm{m}^{3}$. The Moho depths vary from 8.2 to $33.6 \mathrm{~km}$ with the mean of $14.5 \mathrm{~km}$ and the standard deviation is $3.5 \mathrm{~km}$.

\section{Comparison of results with CRUST2.0}

The Moho depths estimated using all three applied numerical schemes were compared with the Moho depths data taken from the global crustal model CRUST2.0 (Bassin et al. 2000); see table 1. The CRUST2.0 Moho depths data (shown in figure 8) vary from 8.6 to $41.8 \mathrm{~km}$ with the mean of $13.5 \mathrm{~km}$ and the standard deviation is $5.4 \mathrm{~km}$.

The differences between the CRUST2.0 and VMM Moho depths estimated using the constant Moho density contrast are shown in figure 9 . These differences vary between -14.1 and $17.9 \mathrm{~km}$ with the mean of $-1.3 \mathrm{~km}$ and the RMS of differences is $5.4 \mathrm{~km}$. The range of the CRUST2.0 Moho depths (of $32.2 \mathrm{~km}$ ) is slightly smaller than the corresponding range of the VMM Moho depths (of $33.2 \mathrm{~km}$ ). The average VMM Moho depth (of $14.8 \mathrm{~km}$ ) is more than $1.3 \mathrm{~km}$ larger than the corresponding average CRUST2.0 Moho depth (of $13.5 \mathrm{~km}$ ). The differences between the CRUST2.0 and VMM Moho depths estimated using the variable Moho density contrast (determined based on applying the Pratt-Hayford isostatic model) are between -15.8 and $15.6 \mathrm{~km}$ with the mean of $-1.9 \mathrm{~km}$, and the RMS of differences is $4.8 \mathrm{~km}$. The spatial distribution of these differences is very similar to the corresponding differences shown in figure 9. The application of the variable Moho density contrast thus does not change significantly the estimated Moho depths. The differences between the CRUST2.0 Moho depths and the corresponding values estimated using the combined least-squares approach are between -9.5 and $9.8 \mathrm{~km}$ with the mean of -0.9 and the RMS of differences is $2.9 \mathrm{~km}$.

Table 1. Comparison of the Moho depths computed using the VMM method (for the constant and variable Moho density contrast) and the combined least-squares (LS) method with the CRUST2.0 Moho depths data.

\begin{tabular}{lrrrr}
\hline Moho depths differences & $\begin{array}{c}\text { Min } \\
(\mathrm{km})\end{array}$ & $\begin{array}{r}\text { Max } \\
(\mathrm{km})\end{array}$ & $\begin{array}{r}\text { Mean } \\
(\mathrm{km})\end{array}$ & $\begin{array}{r}\text { RMS } \\
(\mathrm{km})\end{array}$ \\
\hline CRUST2.0 - VMM (for constant $\Delta \rho)$ & -14.1 & 17.9 & -1.3 & 5.4 \\
CRUST2.0 - VMM (for variable $\Delta \rho)$ & -15.8 & 15.6 & -1.9 & 4.8 \\
CRUST2.0 - LS & -9.5 & 9.8 & -0.9 & 2.9 \\
\hline
\end{tabular}




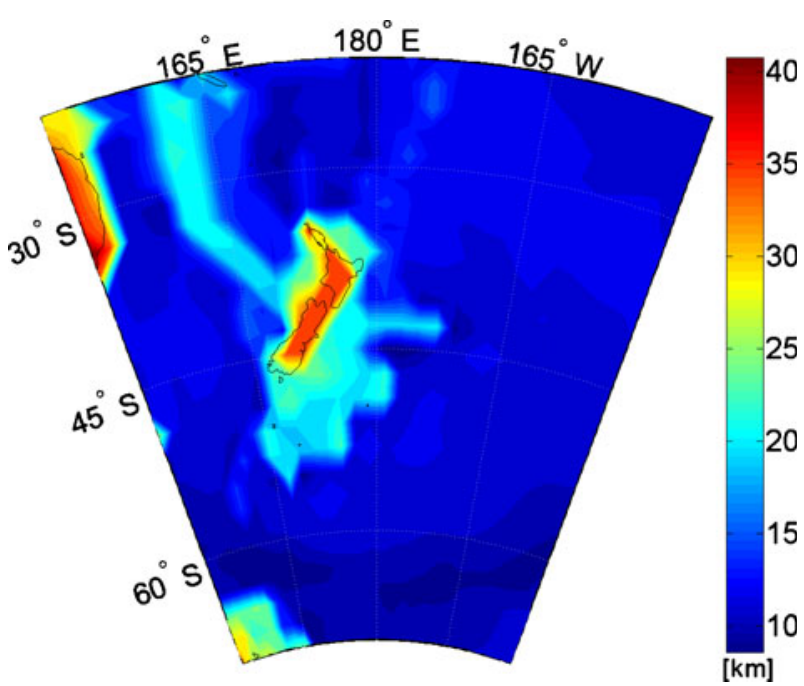

Figure 8. The CRUST2.0 Moho depths.

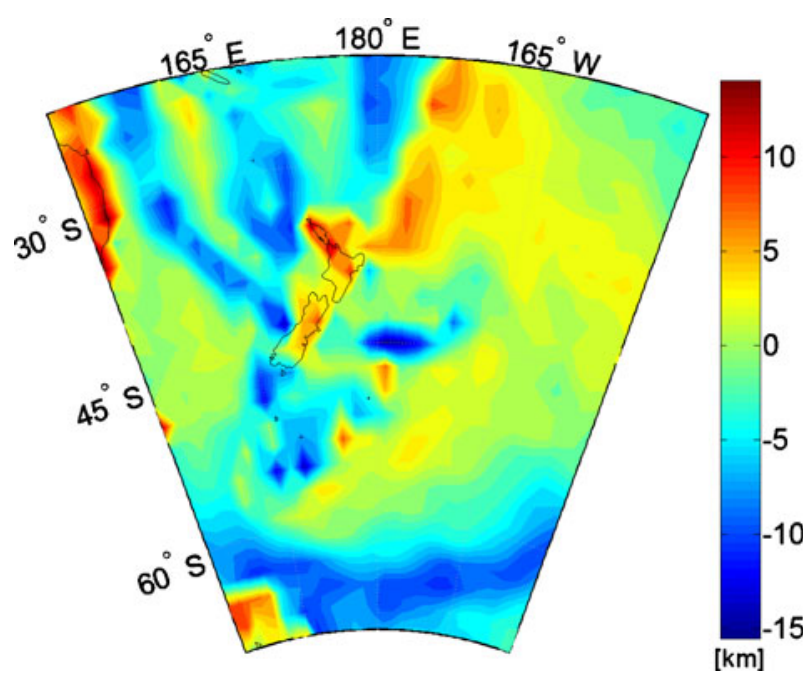

Figure 9. The differences between the CRUST2.0 and VMM Moho depths.

\section{Correlation analysis}

The analysis revealed a high correlation between the Bouguer gravity anomalies and the Moho depths. The total correlation coefficients are 0.99, 0.85 and 0.93 , respectively, for the Moho depths determined based on using the constant Moho density contrast $\Delta \rho$ (VMM isostatic model), the variable Moho density contrast $\Delta \rho$ (Pratt-Hayford model), and the results of the combined leastsquares model. The relation between the refined Bouguer gravity anomalies and the Moho depths is shown in figures 10-12. Although there is almost a proportional change of Moho depths with the Bouguer gravity anomalies when using the constant density contrast $\Delta \rho$, the application of the variable Moho density contrast increased substantially the dispersion while their correlation decreased. The relation between the Bouguer gravity anomalies and the Moho density contrast estimated using the combined least-squares method is demonstrated in figure 13. It is characterized mainly by decreasing values (while increasing dispersion) of the Moho density contrast with the increasing Bouguer gravity anomalies.

The isostatic balance in the VMM model is almost entirely attributed to the depth of compensation. This is evident from a very high correlation between the Moho depths and Bouguer gravity anomalies (figure 10). The correlation substantially decreased after applying the variable Moho density contrast (figure 11). As seen in figures 12 and 13, the isostatic balance is in this case attained by both, the depth and density of compensation. As also seen in figure 12, the maximum continental crust thickness corresponds with the

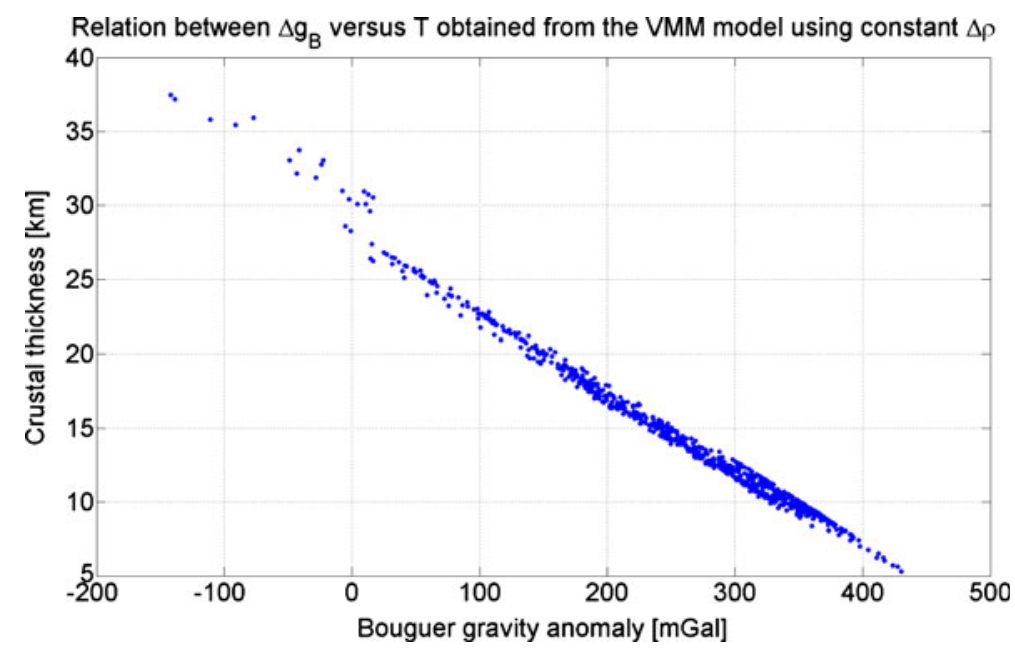

Figure 10. The relation between the refined Bouguer gravity anomalies and the VMM Moho depths obtained based on the constant crust-mantle density contrast (of $400 \mathrm{~kg} / \mathrm{m}^{3}$ ). 


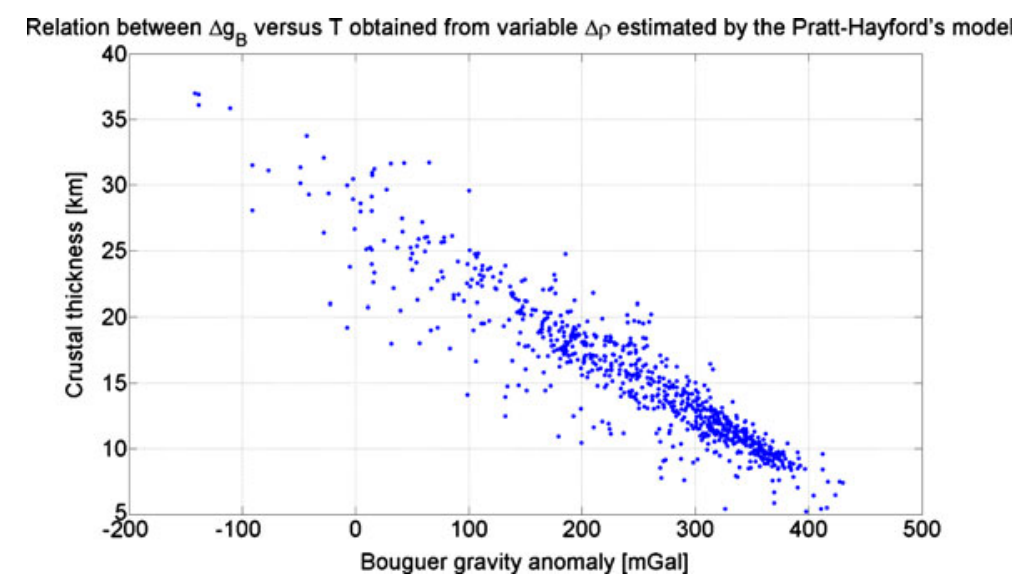

Figure 11. The relation between the refined Bouguer gravity anomalies and the VMM Moho depths obtained based on the variable crust-mantle density contrast estimated using the Pratt-Hayford isostatic model.

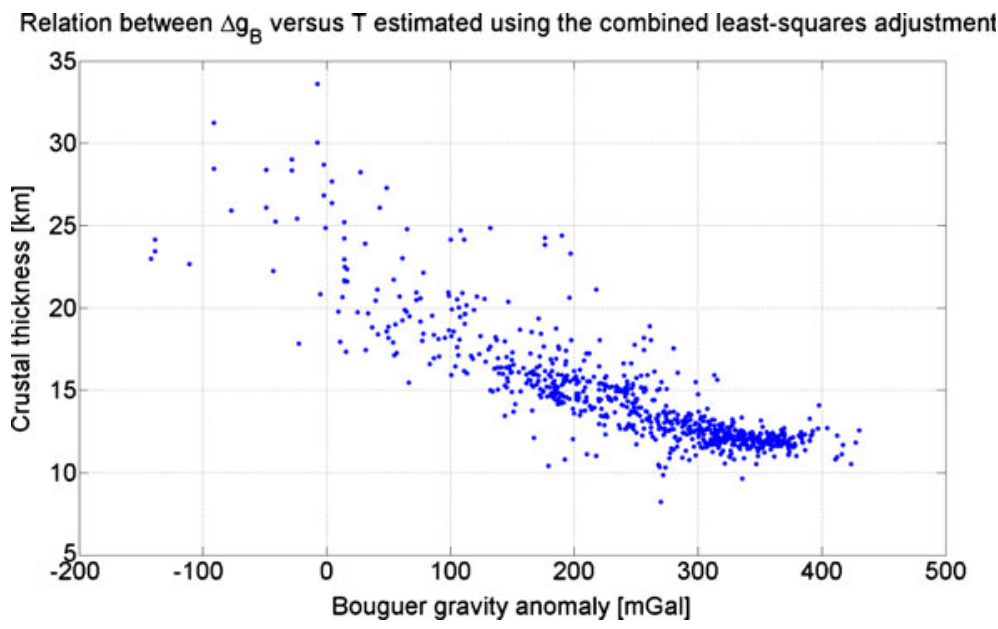

Figure 12. The relation between the refined Bouguer gravity anomalies and the Moho depths estimated using the combined least-squares method.

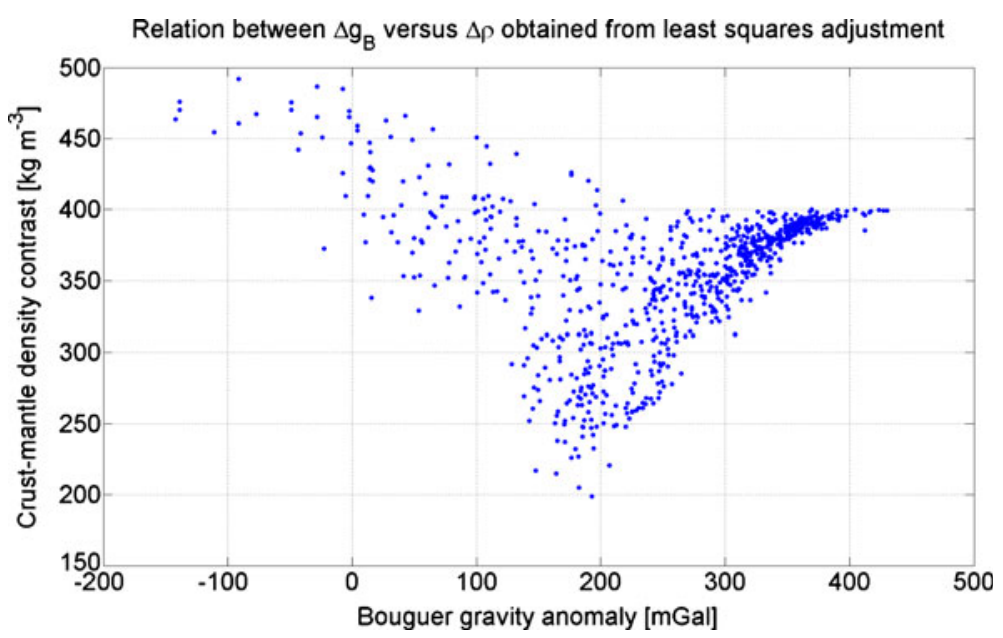

Figure 13. The relation between the refined Bouguer gravity anomalies and the variable crust-mantle density contrast estimated using the combined least-squares method. 
largest negative values of the refined Bouguer gravity anomalies while the oceanic crust is characterized by the largest values of the refined Bouguer gravity anomalies and thinnest crust thickness. As seen in figure 13, the minima of the oceanic Moho density contrast correspond with the values of the refined Bouguer gravity anomalies at the interval within 150 to $220 \mathrm{mGal}$. As seen in figure 2, the maxima of the refined Bouguer gravity anomalies reaching about $400 \mathrm{mGal}$ are situated along the oceanic subduction zone of the Kermadec Trench located north to the North Island of New Zealand.

\section{Discussion}

The comparison revealed that the Moho depths estimated using the combined least-squares approach have the best RMS fit $(2.9 \mathrm{~km})$ with the CRUST2.0 Moho depths. This is a significant improvement compared to the RMS fits between the CRUST2.0 and VMM Moho depths estimated using the constant and variable Moho density contrast. Large errors are expected in the estimated values of the VMM Moho depths due to adopting the constant Moho density contrast. The RMS fit between the CRUST2.0 and VMM Moho depths was in this case $5.4 \mathrm{~km}$. However, even the application of the variable Moho density contrast does not significantly improved the solution. The RMS fit between the CRUST2.0 and VMM Moho depths for the variable Moho density contrast improved only slightly to $4.8 \mathrm{~km}$. The substantial improvement of the accuracy (by means of the RMS fit with CRUST2.0) was thus achieved only when using the simultaneous estimation of both Moho parameters in the least-squares model.

As seen from results, the simultaneous estimation of both Moho parameters in the leastsquares estimation scheme unarguably provides better results than the VMM model. Nevertheless, this model has still serious deficiencies which can lead to an unrealistic estimation of the Moho parameters. The isostatic balance is mathematically formulated for the isostatic gravity anomalies which take into consideration only the topographic mass surplus (topographic gravity correction) and the oceanic mass deficiency (bathymetric stripping gravity correction). Several authors, however, argued that there are additional geophysical contributions attributed to the changing rigidity, glacial isostatic adjustment, plate motion, unmodeled crust density structures and other phenomena which are not taken into consideration in isostatic models. Braitenberg et al. (2006) and Wienecke et al. (2007), for instance, demonstrated that the misfit of the isostatic assumption of the Moho interface to the longwavelength part of the gravity field is explained by large sedimentary basins and rigidity variations of the crustal plate. Kaban et al. (1999) demonstrated that the isostatic compensation does not take place only within the Earth crust but essentially also within the lithospheric mantle. This finding was later also confirmed by Kaban et al. (2004) and Tenzer et al. (2009, 2012). These phenomena thus somehow limit a realistic estimation of the Moho parameters based on using only gravity data. Another limiting factor of the joint inversion technique for the estimation of both Moho parameters is the trade-off between the changes in Moho depths and density contrast (i.e., non-uniqueness of the solution). As consequence, the shallow Moho will preferentially generate density changes, while a deeper Moho will generate geometry changes. This problem can be overcome to some extent by using additional constraining parameters (obtained primarily from seismic surveys). Alternatively, if the seismic data are not available over the study area or their coverage is not sufficient, the long-wavelength part can be subtracted from gravity field used for finding the Moho parameters.

\section{Summary and conclusions}

We have utilized the Vening-Meinesz Moritz, Pratt-Hayford and joint inversion isostatic models in three different numerical schemes of treating the Moho density contrast. The numerical analysis was conducted at the study area of Zealandia. The results were compared with the CRUST2.0 data. We demonstrated that the joint inversion model for the simultaneous estimation of both Moho parameters is more likely the optimal choice. The results obtained based on using this numerical scheme have the best RMS fit with the CRUST2.0 Moho depths. The results of the Vening-Meinesz isostatic model using either the constant or variable Moho density contrast have much larger disagreements with the CRUST2.0 Moho depths.

The significant correlation was found between the Moho geometry and the refined Bouguer gravity data. The largest correlation of 0.99 between these two quantities was obtained when assuming the constant Moho density contrast. When applying the variable Moho density contrast this correlation slightly decreased to 0.85 (Pratt-Hayford model) and 0.93 (combined least-squares model).

The Moho geometry is correlated with the topography (onshore) and the ocean bottom relief (offshore). The largest values of both Moho parameters (if disregarding the parts of Antarctica and Australia) were found beneath Zealandia. Moreover, despite a low spatial resolution used in this 
study, the results indicate that the maxima of the crust thickness are beneath the Southern Alps. This aspect will be investigated in the forthcoming study using a more detailed data resolution. The minima of both Moho parameters correspond with the largest depths throughout Pacific Ocean and Tasman Sea.

The estimated average value of the Moho density contrast $356 \mathrm{~kg} / \mathrm{m}^{3}$ (determined relative to the homogenous crust of the reference density $2670 \mathrm{~kg} / \mathrm{m}^{3}$ ) within the study area is significantly smaller than the corresponding global averages. Tenzer et al. (2011), for instance, estimated that the average value of the global Moho density contrast is $485 \mathrm{~kg} / \mathrm{m}^{3}$. This value very closely agrees with the value of $480 \mathrm{~kg} / \mathrm{m}^{3}$ adopted in the definition of the Preliminary Reference Earth Model (PREM; Dziewonski and Anderson 1981). This value differs by about $7 \%$ from the global average of the Moho density contrast of $448 \pm 187 \mathrm{~kg} / \mathrm{m}^{3}$ estimated by Sjöberg and Bagherbandi (2011) based on solving the VMM isostatic model. However, the crust-mantle density contrast varies significantly. They also showed that the Moho density contrast varies globally from $81.5 \mathrm{~kg} / \mathrm{m}^{3}$ in the Pacific region to $988 \mathrm{~kg} / \mathrm{m}^{3}$ in Tibet, with the average values of $678 \pm 78 \mathrm{~kg} / \mathrm{m}^{3}$ and $334 \pm 108 \mathrm{~kg} / \mathrm{m}^{3}$ for the continental and oceanic areas, respectively.

\section{Acknowledgements}

The authors acknowledge Prof Lars E Sjöberg for useful comments, guidance and help. Mohammad Bagherbandi was supported by the Project no. 76/10:1 of the Swedish National Space Board (SNSB).

\section{References}

Bassin C, Laske G and Masters T G 2000 The current limits of resolution for surface wave tomography in North America; EOS Trans AGU 81 F897.

Bagherbandi M and Sjöberg L E 2011 Comparison of crustal thickness from two isostatic models versus CRUST2.0; Stud. Geophys. Geod. 55 641-666.

Bjerhammar A 1962 On an explicit solution of the gravimetric boundary value problem for an ellipsoidal surface of reference; Technical Report, The Royal Institute of Technology, Division of Geodesy, Stockholm.
Braitenberg C, Wienecke S and Wang Y 2006 Basement structures from satellite derived gravity field: The South China Sea Ridge; J. Geophys. Res. 111 B05407.

Dziewonski A M and Anderson D L 1981 Preliminary reference earth model; Phys. Earth Planet. Inter. 25 $297-356$.

Heiskanen W A and Vening Meinesz F A 1958 The Earth and its Gravity Field; McGraw-Hill Book Company, Inc.

Heiskanen W A and Moritz H 1967 Physical Geodesy; Freeman W.H. and Co., San Francisco and London, 364p.

Hinze W J 2003 Bouguer reduction density, why 2.67?; Geophysics 68(5) 1559-1560.

Kaban M K, Schwintzer P and Tikhotsky S A 1999 Global isostatic gravity model of the Earth; Geophys. J. Int. 136 519-536.

Kaban M K, Schwintzer P and Reigber Ch 2004 A new isostatic model of the lithosphere and gravity field; J. Geod. 78 368-385.

Moritz H 1990 The Figure of the Earth; H Wichmann, Karlsruhe, 277p.

Pavlis N K, Factor J K and Holmes S A 2007 Terrainrelated gravimetric quantities computed for the next EGM; In: Gravity Field of the Earth (eds) Kiliçoglu A and Forsberg R, Proceedings of the 1st International Symposium of the International Gravity Field Service (IGFS), Harita Dergisi, Special Issue No. 18, General Command of Mapping, Ankara, Turkey.

Pavlis N, Holmes S A, Kenyon S C and Factor J K 2008 An earth gravitational model to degree 2160: EGM08; Presented at the 2008 General Assembly of the European Geosciences Union, Vienna, Austria, April 13-18.

Sjöberg L E 2009 Solving Vening Meinesz-Moritz inverse problem in isostasy; Geophys. J. Int. 179(3) 1527-1536.

Sjöberg L E and Bagherbandi M 2011 A method of estimating the Moho density contrast with a tentative application by EGM08 and CRUST2.0.; Acta Geophys. 59(3) 502-525.

Sjöberg L E and Bagherbandi M 2012 Comparison of crustal thickness from two gravimetric-isostatic models and CRUST2.0.; Studia Geophys. Geod., doi: 10.1007/ s11200-010-9030-0.

Tenzer R, Hamayun and Vajda P 2009 Global maps of the CRUST2.0 crustal components stripped gravity disturbances; Geophys, J., Res. 114B 05408.

Tenzer R, Hamayun, Novák P, Gladkikh V and Vajda P 2011 Global crust-mantle density contrast estimated from EGM2008, DTM2008, CRUST2.0, and ICE-5G; Pure Appl. Geophys., doi: 10.1007/s00024-011-0410-3.

Tenzer R, Gladkikh V, Vajda P and Novák P 2012 Spatial and spectral analysis of refined gravity data for modelling the crust-mantle interface and mantle-lithosphere structure; Surv. Geophys., doi: 10.1007/s10712-012-9173-3.

Vening Meinesz F A 1931 Une nouvelle methode pour la reduction isostatique regionale de l'intensite de la pesanteur; Bulletin Géodésique 29 33-51.

Wienecke S, Braitenberg C and Götze H-J 2007 A new analytical solution estimating the flexural rigidity in the Central Andes; Geophys. J. Int. 169(3) 789-794. 